ఠ

\title{
Health literacy and the Affordable Care Act: a policy analysis for children with special health care needs in the USA
}

This article was published in the following Dove Press journal:

Risk Management and Healthcare Policy

7 April 2015

Number of times this article has been viewed

\author{
Jessica Keim-Malpass' \\ Lisa C Letzkus ${ }^{1,2}$ \\ Christine Kennedy'
}

'University of Virginia School of Nursing, ${ }^{2}$ University of Virginia Children's Hospital, Charlottesville, VA, USA
Correspondence: Jessica Keim-Malpass University of Virginia School of Nursing, PO Box 800782, Charlottesville,

VA 22908, USA

Tel +l 6363466855

Fax + I 4349242787

Email jik2t@virginia.edu

\begin{abstract}
Children with special health care needs $(\mathrm{CSHCN})$ represent populations with chronic health conditions that are often high utilizers of health care. Limited health literacy has emerged as a key indicator of adverse health outcomes, and CSHCN from limited health literacy families are particularly vulnerable. The purpose of this policy analysis is to outline key provisions in the Affordable Care Act (ACA) that incorporate health literacy approaches for implementation and have implications for CSHCN in the USA. Several key provisions are incorporated in the ACA that involve health literacy and have implications for CSHCN. These include: expansion of public insurance coverage and simplifying the enrollment process, provisions assuring equity in health care and communication among all populations, improving access to patient-centered medical homes that can offer care coordination, ensuring enhanced medication safety by changing liquid medication labeling requirements, and provisions to train health care providers on literacy issues. More research is needed to determine how provisions pertaining to health literacy in the ACA are implemented in various states.
\end{abstract}

Keywords: children, special health care needs, health literacy, Affordable Care Act, health policy

\section{Children with special health care needs}

Children with special health care needs ( $\mathrm{CSHCN})$ have been defined as those who have, or are at increased risk for a chronic physical, developmental, behavioral, or emotional condition and who require health-related services beyond that required by children generally. ${ }^{1,2}$ It is estimated that nearly $13 \%-18 \%$ of children in the USA are CSHCN, yet they account for $40 \%-70 \%$ of all health care expenditures among children. ${ }^{1,3-6}$ While this definition includes many pediatric diagnoses over all demographic groups, there is an identified link between poverty and CSHCN. ${ }^{7}$

To date, most of the research regarding CSHCN in the USA has been limited to two large nationwide surveys that have described key access to care issues due to lack of coordination between primary and specialty providers, unmet needs regarding access to patient-centered medical homes, financial costs associated with caring for a child with special health care needs, and family-level disparities due to both direct medical costs and loss of days at work. ${ }^{1,2}$ During the past decade, significant steps have been taken to ensure health care coverage for CSHCN through programs like the Children's Health Insurance program (CHIP), Medicaid, and other policy-based state and federal programs; however, there is still a defined need for coordination of specialty and primary care providers and high-quality, family-centered approaches to care in this population. ${ }^{8}$ Over $33 \%$ of families of CSHCN report their health coverage is inadequate and 
places their family at financial risk. ${ }^{4}$ Most of these described challenges focus on inadequate access to medical specialists, inadequate coverage of wrap-around (ancillary) services, and unreasonable uncovered or out-of-pocket costs. ${ }^{4}$

Family-level attributes that predict successful clinical outcomes and high-quality care among CSHCN are substantially less understood and represent a defined gap in the literature. Of these family-level attributes, caregiver health literacy, or "the degree to which an individual has the capacity to obtain, communicate, process, and understand health information and services in order to make appropriate health decisions", has been identified as a key predictor of child health outcomes and health care utilization. ${ }^{9,10}$

\section{Health literacy and the Affordable Care Act}

Health literacy is recognized by the Institute of Medicine as an integral component of high-quality health care and it is estimated that $36 \%$ of all adults in the USA have limited health literacy; the prevalence increases to around $50 \%$ among those who are also from a low income background. ${ }^{9}$ In pediatric populations, it is estimated that one in three caregivers/parents has limited or marginal literacy skills, meaning that they have difficulty using complex texts to accomplish everyday tasks and lack the skills necessary for full participation in health care settings. ${ }^{10,11}$ Limited health literacy families have not been well studied in pediatric populations with complex illnesses, such as CSHCN. ${ }^{12}$ Despite the fact that CSHCN have varied treatment trajectories, prolonged periods of hospitalizations, and complicated home medication regimens, there is little information available on the role that limited health literacy has on long-term clinical outcomes, such as successful chronic disease management, health care utilization, and adherence to medical recommendations. Additionally, very few studies have evaluated the relationship between the health literacy and health service use of caregivers and access to coordinated services among their children, even though these relationships have been established in several adult populations. ${ }^{12}$

While salient research questions remain to be answered within the context of health literacy among families of CSHCN, there are also many direct policy linkages that persist among this population. The passing of the Patient Protection and Affordable Care Act (ACA) has led to extensive reforms that impact families of CSHCN, most notably regarding expansion of Medicaid and CHIP eligibility that is still in the process of being interpreted and implemented at the state level. ${ }^{13}$ While increasing access to health care coverage and reducing gaps in Medicaid eligibility should be applauded, the ACA also has direct and indirect policy provisions that include health literacy, which have not yet been examined. The purpose of this policy analysis is to identify and discuss key provisions in the ACA that incorporate health literacy approaches and have direct implications for CSHCN and their families. A policy discourse analysis was conducted among primary sources of data from the $\mathrm{ACA}^{14}$ as well as secondary data sources, including white papers from health literacy and child health advocacy groups, commentaries from medical journals, and textual data on blog sites from lay health consumers.

\section{Provisions of the Affordable Care Act with health literacy applications}

Health literacy is directly mentioned in four sections of the ACA (Table 1). These provisions include: dissemination of research regarding health care quality measures, enhancing shared decision-making strategies, proposed advocacy regarding changes in medication labeling, and workforce development inclusive of health literacy strategies. ${ }^{15}$ Possible benefits and positive outcomes of these provisions for CSHCN are presented in Table 1.

There are several key areas where indirect provisions of the ACA could have health literacy implications for CSHCN (Table 2). These content areas include: extending health insurance coverage, innovations in quality, delivery and cost of care, workforce development, and health information strategies. The ACA sections, key defining components, and health literacy implications for CSHCN are also presented in Table 2.

\section{Implementation considerations}

In regards to health literacy-specific programming and evaluation, the ACA is not a strong legislative change agent for health literacy inclusion or health literacy-specific reforms. Most notably, the legislative language alludes to health literacy in several key areas, but it is mentioned within a consultative model only, without any regulatory mandates or associated financial provisions. None of the direct mentions of health literacy include it within the scope of health literacyspecific programming. Especially disappointing within the context of nursing care delivery and nursing education is the lack of health literacy inclusions in workforce development strategies, which could include primary care nurse practitioners (both family and pediatric) or pre-licensure education of registered nurses, but only include physicians. The workforce development areas were allocated $\$ 125$ million in the form 
Table I Direct mentions of health literacy in the Affordable Care Act

\begin{tabular}{|c|c|c|c|c|}
\hline Section & Title & Provision & $\begin{array}{l}\text { Possible outcomes } \\
\text { for CSHCN }\end{array}$ & $\begin{array}{l}\text { Program vs } \\
\text { consultation }\end{array}$ \\
\hline 3501 & $\begin{array}{l}\text { Health Care } \\
\text { Delivery, System } \\
\text { Research, Quality } \\
\text { Improvement } \\
\text { Technical Assistance }\end{array}$ & $\begin{array}{l}\text { Research from AHRQ's Center for Quality } \\
\text { Improvement and Patient Safety be made } \\
\text { "available to the public through multiple media } \\
\text { and appropriate formats to reflect the varying } \\
\text { needs of health care providers and consumers } \\
\text { and diverse levels of health literacy." }\end{array}$ & $\begin{array}{l}\text { More transparency regarding } \\
\text { quality outcomes in children's } \\
\text { hospitals and pediatric primary } \\
\text { care and specialty care settings. }\end{array}$ & $\begin{array}{l}\text { Consultation with health } \\
\text { literacy experts }\end{array}$ \\
\hline 3506 & $\begin{array}{l}\text { Program to facilitate } \\
\text { shared decision } \\
\text { making }\end{array}$ & $\begin{array}{l}\text { Amends the Public Health Service Act } \\
\text { to authorize a "program to update patient } \\
\text { decision aids to assist health care providers } \\
\text { and patients." (Administered by the CDC } \\
\text { and NIH to develop, update, and produce } \\
\text { patient decision aids for preference-sensitive } \\
\text { care to assist providers in educating patients } \\
\text { and caregivers regarding efficacy and cost of } \\
\text { treatment and palliative approaches. "Decision } \\
\text { aids must reflect varying needs of consumers } \\
\text { and diverse levels of health literacy." }\end{array}$ & $\begin{array}{l}\text { Decision aids could be developed } \\
\text { for limited health literacy families } \\
\text { or to help engage in shared } \\
\text { decision-making - both } \\
\text { for treatment decisions and for } \\
\text { decisions at the end of life for } \\
\text { CSHCN with life-limiting } \\
\text { diagnoses. }\end{array}$ & $\begin{array}{l}\text { Consultation with health } \\
\text { literacy experts; section } \\
\text { authorized but not } \\
\text { funded }\end{array}$ \\
\hline 3507 & $\begin{array}{l}\text { Presentation of } \\
\text { Prescription Drug } \\
\text { Benefit and Risk } \\
\text { Information }\end{array}$ & $\begin{array}{l}\text { Determines whether the addition of } \\
\text { information on drug labeling and print } \\
\text { advertising will help consumers; to consult } \\
\text { with various stakeholders and "experts in } \\
\text { health literacy." }\end{array}$ & $\begin{array}{l}\text { Proposes changes in drug labeling } \\
\text { standards - in particular liquid } \\
\text { medication - that could decrease } \\
\text { medical error rates for limited } \\
\text { literacy caregivers of CSHCN. }\end{array}$ & $\begin{array}{l}\text { Consultation with health } \\
\text { literacy experts. FDA } \\
\text { currently leading studies, } \\
\text { literature review and } \\
\text { consultation. First report } \\
\text { to Congress in 2011. }\end{array}$ \\
\hline 5301 & $\begin{array}{l}\text { Training in Family } \\
\text { Medicine, General } \\
\text { Internal Medicine, } \\
\text { General Pediatrics } \\
\text { and Physician assistant. }\end{array}$ & $\begin{array}{l}\text { Amends Title VII of the Public Health Service } \\
\text { Act to make training grants available to primary } \\
\text { medical specialties that "provide training in } \\
\text { enhanced communication with patients ... and } \\
\text { in cultural competence and health literacy." }\end{array}$ & $\begin{array}{l}\text { Potential to infuse health literacy } \\
\text { as a key health concept in } \\
\text { medical training for pediatricians } \\
\text { and family medicine physicians } \\
\text { who care for CSHCN. }\end{array}$ & $\begin{array}{l}\text { Programmatic, direct } \\
\$ \text { allocation } \\
\$ 125 \text { million through } \\
2014 \text { for entire section }\end{array}$ \\
\hline
\end{tabular}

Note: Copyright $\odot$ 2010. Adapted from Center for Health Care Strategies, Inc. Somers SA, Mahadevan R. Health Literacy Implications of the Affordale Care Act. Center for Health Care Strategies. November 2010.15

Abbreviations: CSHCN, children with special health care needs; FDA, US Food and Drug Administration; CDC, Centers for Disease Control and Prevention; NIH, National Institutes of Health; AHRQ, Agency for Healthcare Research and Quality; vs, versus.

Table 2 Indirect provisions related to health literacy that could have implications for CSHCN in the Affordable Care Act

\begin{tabular}{lll}
\hline Content area/ACA sections & Components & Health literacy implications for CSHCN \\
\hline Extending health insurance coverage & I. Individual mandate for health insurance coverage; & Simplify the CHIP and Medicaid enrollment \\
(Sections I002, II $03,13 \mid \mathrm{I}, 14 \mathrm{I3}$, & 2. employer mandates; 3. regional/state exchanges; & process; 90 percent of states currently have \\
$27 \mid 5,3306)$ & $\begin{array}{l}\text { 4. expansion of Medicaid eligibility; 5. extending dependent } \\
\text { coverage; 6. eliminating lifetime limits on coverage; }\end{array}$ & readability guidelines for Medicaid \\
& enrollment documentation
\end{tabular}

7. prohibiting the denial of coverage with children with pre-existing conditions; 8. regulation of annual dollar limits on insurance coverage

Innovations in quality, delivery and cost of care (Sections 2703, 30II, 30I2, 30I3, 3014, 3015, 302I, 350I, 3502, 3506, 3510, 10331, 10333) Workforce development (Sections $5205,5301,5307,5313,5402,5403$, 5507,5606 )

Health information (Sections 3305, 3503, 3507, 4205, 10328)
I. A national approach in establishing a federal inter-agency quality workgroup; 2 . Changes in delivery through improved care coordination and patient-centered medical homes; 3. cost reduction through pay-for-performance strategies I. Scholarships, grants, and loan repayment for health care professionals in primary care and mental health; 2 . Offers continuing education for health professionals who serve minority, rural and other special populations; 3 . Improves medical school curricula in the areas of cultural competency and interprofessional education I. Standards for nutrition labeling; 2 . Assess if changes are needed in the presentation of prescription drug information
Establish the medical home model of care for $\mathrm{CSHCN}$ and tailor services in medical home care delivery model for limited-literacy caregivers

Advocate for health literacy training (incorporating the use of plain language, 'teach back' modalities, etc) as a required competency for those training in pediatrics

Establish national standards for safe-use labeling of pediatric liquid medications

Note: Copyright $\odot$ 2010. Adapted from Center for Health Care Strategies, Inc. Somers SA, Mahadevan R. Health Literacy Implications of the Affordale Care Act. Center for Health Care Strategies. November 2010.15

Abbreviations: ACA, Affordable Care Act; CSHCN, children with special health care needs; CHIP, children's health insurance program. 
of loans, grants, and loan repayments to recruit physicians and physician assistants into primary care, and the legislative language does highlight training in cultural competence and health literacy, but the direct money allocation is not healthliteracy specific.

Opportunity exists within health sciences education to incorporate health literacy training that would include clinicians who directly interface with $\mathrm{CSHCN}$ in a variety of care settings. In a recent survey of pediatric providers, more than $75 \%$ reported no regular use of evidence-based communication skills, such as teach-back methodology, reducing medical jargon, and using drawings to enhance verbal communication. ${ }^{16}$ To fully realize the health-literacy specific goals outlined in ACA Section 5301 for pediatric providers, there should be specific coordinated efforts between the Department of Health and Human Services, Health Resources and Services Administration, and medical and nursing organizations to make health literacy training a required component of post-graduate training in child health and to disseminate evidence-based health literacy training modules for pediatric providers, trainees, and nurses. ${ }^{16}$

Another opportunity for enhanced safety of CSHCN falls under ACA Section 3507, which authorizes the Department of Health and Human Services to consider alternative strategies for medication labeling, inclusive of strategies for individuals with limited health literacy. The US Food and Drug Administration published its final report to Congress based on this provision in 2011. The report did not imply any large shifts in reporting strategies, delaying decisions until the consultation and empirical research is completed. ${ }^{17}$ Medication errors are more likely in families with limited health literacy skills, and previous research has demonstrated that errors associated with dosing of pediatric liquid medications are common. ${ }^{18-20}$ Yin et $\mathrm{al}^{20}$ found that $23 \%$ of caregivers used non-standardized liquid dosing and nearly 68\% were unaware of weight-based dosing for children. CSHCN often have complicated home medication regimens, and strategies that would change both non-prescription and prescription information and ease of dosing would potentially have a large impact on medication safety in this population.

Arguably the largest impact of the ACA for CSHCN focuses on the extension of health care coverage through expansion of Medicaid and CHIP eligibility, and the individual and employer health insurance mandates. There are at least nine million children in the USA who are uninsured, and of those, at least five million are eligible for public insurance through Medicaid or CHIP. ${ }^{21}$ Individual states are still in the process of determining whether to expand Medicaid.
They are also still interpreting and developing implementation strategies for state and federal exchanges, Medicaid managed care plans, and CSHCN-specific programming. ${ }^{22-24}$ While there is no direct language in the ACA regarding health literacy strategies to enhance enrollment for health care coverage, there is a need to promote strategies for enrollment that include families with limited health literacy. Previous research has demonstrated that the average Medicaid and CHIP applications and renewal applications range between 11 th to 18 th grade (despite recommended reading levels ranging between 5 th and 6th grade), use font sizes below 12 point, and have crowded formatting and excessively high reading demands. ${ }^{25-28}$ Outreach strategies for enrollment in health care insurance coverage (both public and private) that incorporate alternative strategies for enrollment and resources for limited health literacy are critical for CSHCN families..$^{29,30}$

\section{Unifying themes}

Even with mediocre direct legislative language, there are many opportunities to incorporate best-practice strategies that include health literacy considerations and evidence-based models of care to improve health care access and delivery for CSHCN. Unifying themes are found throughout the ACA that include patient-centered care and quality health communication. ${ }^{15}$ Research has demonstrated that the children of limited literacy caregivers are at the greatest risk for low-quality and uncoordinated health care. ${ }^{16}$ Within the past decade, the American Academy of Pediatrics has defined the patient-centered medical home as the optimal model for delivery of primary care. ${ }^{31,32}$ The medical home model of care consists of the following: accessibility, family-centeredness, continuity, comprehensiveness, coordination, compassion, and cultural effectiveness. ${ }^{32}$ Patient-centered medical homes provide each patient with a provider who leads and integrates an interdisciplinary care team to facilitate care across various services and settings. ${ }^{33}$ While development of the medical home model was directed toward delivery of care for all children, it is increasingly cited as the fundamental component of improved quality care delivery for CSHCN to need to coordinate between primary and specialty care providers.

The ACA did include direct provisions for use of the Medicare Shared Savings Program to broadly implement Accountable Care Organization (ACO) models, with the hope of aligning ACOs with the patient-centered medical home model (ACA Section 3022). ${ }^{34}$ Thus, ACOs agree to be accountable for the overall care, costs, and quality of care for patients enrolled in their services. The financial 
structure incentive payments are determined by comparing the organizations annual incurred costs to Centers for Medicare and Medicaid Services-established costs that are benchmarked against quality of care best practices. ${ }^{34}$ Implementing the medical home model (particularly if administered within the context of an ACO) presents a unique opportunity to mitigate disparities associated with limited health literacy for CSHCN by: incentivizing health literacy workforce education within its system, making health information more accessible and easier to understand for patients and families, appropriate screening for limited health literacy families, facilitating health literacy quality improvement projects, and engaging families in shared decision-making.

It has been estimated that limited health literacy adds an additional $3 \%-5 \%$ of the total health care cost per year per individual with limited health literacy. ${ }^{35}$ Thus, there is significant financial incentive for ACOs to mitigate the financial impact of limited health literacy among caregivers of CSHCN, particularly because they are already high utilizers of the health care system. To date, most of the research surrounding caregiver health literacy has focused on health promotion, and more research is needed to determine if there are meaningful ways to modify the social determinants of coordination of quality of care for $\mathrm{CSHCN}$, with a particular focus on: coordination of specialist care, care delivery during periods of transition, information needs that persist among these families, medication adherence, and quality discharge planning from acute care settings. Medical homes represent an optimal strategy for implementing and testing how health literacy can be incorporated in this model of enhanced care delivery.

\section{Conclusion}

Health care providers who regularly provide care for CSHCN have a unique opportunity to provide leadership on implementation of key health provisions for improved quality of care among limited health literacy families of CSHCN in the USA. The existing legislative language in the ACA that includes health literacy is weak and primarily exists as a consultative (not programmatic) provision. However, incorporating health literacy strategies into patient-centered medical home models for CSHCN provides an exciting opportunity for health care providers. As the implementation of the ACA continues to unfold, additional policy and health services research is needed to determine how this legislation is interpreted, and the impacts (intended and unintended) of those interpretations in the various states.

\section{Acknowledgments}

The authors would like to acknowledge Elayne K Phillips for her thoughtful editorial review. We would also like to acknowledge the MH Sly Endowed Professor research funds from the University of Virginia School of Nursing.

\section{Disclosure}

The authors report no conflicts of interest in this work.

\section{References}

1. Van DyckPC, Kogan MD, McPherson MG, Weissman GR, NewacheckPW Prevalence and characteristics of children with special health care needs Arch Pediatr Adolesc Med. 2004;158(9):884-890.

2. Van Dyck PC, McPherson M, Strickland BB, et al. The national survey of children with special health care needs. Ambul Pediatr. 2010;2(1): 29-37.

3. Strickland BB, Singh GK, Kogan MD, Mann MY, van Dyck PC, Newacheck PW. Access to the medical home: new findings from the 2005-2006 National Survey of Children with Special Health Care Needs. Pediatrics. 2009;123(6):e996-e1004.

4. Newacheck PW, Kim SE. A national profile of health care utilization and expenditures for children with special health care needs. Arch Pediatr Adolesc Med. 2005;159(1):10-17.

5. Newacheck P, Strickland B, Shonkoff J, et al. An epidemiologic profile of children with special health care needs. Pediatrics. 1998;102(1): $117-123$.

6. Perrin JM. Health services research for children with disabilities. Milbank Q. 2002;80(2):303-324.

7. Farrall K, Hess C, Justice D. The Affordable Care Act and children with special health care needs: an analysis and steps for state policymakers. 2011. Available from: http://www.nashp.org/sites/ default/files/aca.children.special.hcneeds.pdf. Accessed February 4, 2015.

8. Honberg L, McPherson M, Strickland B, Gage JC, Newacheck PW Assuring adequate health insurance: results of the National Survey of Children with Special Health Care Needs. Pediatrics. 2005;115(5): 1233-1239.

9. Nielsen-Bohlman L, Panzer AM, Hamlin B, Kindig DA. Health literacy: a prescription to end confusion, 2004. Retrieved from http://iom.edu/ Reports/2004/Health-Literacy-A-Prescription-to-End-Confusion.aspx. Accessed February 4, 2015.

10. Sanders LM, Federico S, Klass P, Abrams MA, Dreyer B. Literacy and child health: a systematic review. Arch Pediatr Adolesc Med. 2009; 163(2):131-140.

11. Paasche-Orlow MK, Parker RM, Gazmararian JA, Nielsen-Bohlman LT, Rudd RR. The prevalence of limited health literacy. J Gen Intern Med. 2005;20(2):175-184.

12. DeWalt DA, Hink A. Health literacy and child health outcomes: a systematic review of the literature. Pediatrics. 2009;124 Suppl:S265-S274.

13. Sommers BD, Graves JA, Swartz K, Rosenbaum S. Medicaid and marketplace eligibility changes will occur often in all states; policy options can ease impact. Health Aff (Millwood). 2014;33(4): 700-707.

14. The Library of Congress [homepage on the Internet]. HR 3590 Patient Protection and Affordable Care Act. Bill Text, 111th Congress (2009-2010). Available from: http://thomas.loc.gov/cgi-bin/ query/z?c111:H.R.3590:. Accessed March 2, 2014.

15. Somers SA, Mahadevan R. Health Literacy Implications of the Affordable Care Act. Hamilton, NJ: Center for Health Care Strategies, Inc.; 2010. Available from: http://www.chcs.org/media/Health_Literacy_ Implications_of_the_Affordable_Care_Act.pdf. Accessed February 4, 2015. 
16. Sanders L. Health literacy and the health reform: where do children fit in? In: Wizemann T, editor. Health Literacy Implications for Health Care Reform: Workshop Summary, Institute of Medicine. Washington, DC, USA: The National Academies Press; 2011. Available from: http:// www.nap.edu/openbook.php?record_id=13056\&page=101. Accessed February 4, 2015.

17. US Food and Drug Administration. Implementation of Section 3507 of the Patient Protection and Affordable Care Act of 2010. Available from: http:/www.fda.gov/downloads/AboutFDA/CentersOffices/OfficeofMedicalProductsandTobacco/CDER/ReportsBudgets/UCM388282. pdf. Accessed February 4, 2015.

18. Bailey SC, Pandit AU, Yin S, et al. Predictors of misunderstanding pediatric liquid medication instructions. Fam Med. 2004;41(10):715-721.

19. Yin H, Dreyer B, Foltin G, Schaick L, Mendelsohn A. Association of low caregiver health literacy with reported use of nonstandardized dosing instruments and lack of knowledge of weight-based dosing. Ambul Pediatr. 2007;7(4):292-298.

20. Yin HS, Dreyer BP, Moreira HA, et al. Liquid medication dosing errors in children: role of provider counseling strategies. Acad Pediatr. 2014; 14(3):262-270.

21. Holahan J, Cook A, Dubay L. Characteristics of the uninsured: who is eligible for public coverage and who needs help affording coverage, 2007. Available from: https://kaiserfamilyfoundation.files.wordpress. com/2013/01/7613.pdf. Accessed February 4, 2015.

22. Rosenbaum $\mathrm{S}$. The Patient Protection and Affordable Care Act and the future of child health policy. Acad Pediatr. 2012;12(5):363-364.

23. Catalyst Center. The Affordable Care Act and children with special health care needs: an analysis and steps for state policymakers. 2011. Available from: http:/hdwg.org/sites/default/files/ACAandCSHCNpaper.pdf. Accessed October 15, 2014.

24. Hahn JA, Sheingold BH. Medicaid expansion: the dynamic health care policy landscape. Nurs Econ. 2014;31(6):267-272.
25. Wilson JM, Wallace LS, DeVoe JE. Are state Medicaid application enrollment forms readable? J Health Care Poor Underserved. 2009;20(2):423-431.

26. Wallace LS, DeVoe JE, Hansen JS. Assessment of Children's Public Health Insurance Program enrollment applications: a health literacy perspective. J Pediatr Health Care. 2011;25(2):133-137.

27. Pati S, Kavanagh JE, Bhatt SK, Wong AT, Noonan K, Cnaan A. Reading level of Medicaid renewal applications. Acad Pediatr. 2012;12(4): 297-301.

28. Feinberg E, Swartz K, Zaslavsky AM, Gardner J, Walker DK. Language proficiency and the enrollment of Medicaid-eligible children in publicly funded health insurance programs. Matern Child Health J. 2002;6(1): 5-18.

29. Martin LT, Parker RM. Insurance expansion and health literacy. JAMA. 2011;306(8):874-875.

30. Hewitt M. Facilitating state health exchange communication through the use of health literate practices: workshop summary, Institute of Medicine. Washington, DC, USA: The National Academies Press; 2012.

31. American Academy of Pediatrics. Policy statement: the medical home. Pediatrics. 2002;110(1):184-186.

32. American Academy of Pediatrics. Policy statement: organizational principles to guide and define the child health care system and/or improve health of all children. Pediatrics. 2004;113:1545-1547.

33. Korda H, Eldridge GN. ACOs, PCMHs, and health care reform: nursing's next frontier? Policy Polit Nurs Pract. 2011;12(2):100-103.

34. Barnes AJ, Unruh L, Chukmaitov A, van Ginneken E. Accountable care organizations in the USA: types, developments and challenges. Health Policy. 2014;118(1):1-7.

35. Eichler K, Wieser S, Brügger U. The costs of limited health literacy: a systematic review. Int J Public Health. 2009;54(5):313-324.

\section{Publish your work in this journal}

Risk Management and Healthcare Policy is an international, peerreviewed, open access journal focusing on all aspects of public health, policy, and preventative measures to promote good health and improve morbidity and mortality in the population. The journal welcomes submitted papers covering original research, basic science, clinical \& epidemio-

\section{Dovepress}

logical studies, reviews and evaluations, guidelines, expert opinion and commentary, case reports and extended reports. The manuscript management system is completely online and includes a very quick and fair peerreview system, which is all easy to use. Visit http://www.dovepress.com/ testimonials.php to read real quotes from published authors. 